\title{
Penerapan Metode Weighted Product Untuk Penentuan Penerima Beasiswa Peserta Didik
}

\author{
Arief Dhiemas Suryanto ${ }^{1 *}$, Alam Supriyatna ${ }^{2}$ \\ ${ }^{1}$ STIKOM Binaniaga/Sistem Informasi \\ Email: ariefdhimas@gmail.com \\ ${ }^{2}$ STIKOM Binaniaga/Sistem Informasi \\ Email: alam@stikombinaniaga.ac.id
}

\begin{abstract}
In determining the scholarship recipients of disadvantaged students. Where each student who wants to apply for underprivileged scholarships will be surveyed by the Observer appointed by the school to the residence of students. In the survey process, the Observer is provided with an assessment instrument that must be filled in accordance with the real conditions of the student's residence. The results of the assessment are given to the scholarship manager. The main problem in this development is the process used in determining the recipients of scholarships that are less than optimal and the way that is done in processing scholarship data for students is less effective and efficient. The objectives in this development are: Optimizing the process of determining scholarship recipients by applying the weighted product method in calculating the value of the survey results and making effective and efficient ways of processing scholarship data for students who are less capable and in the form of applications. The method used in this application is the WP (Weighted product) method. Implementation In developing applications, the Prototype method is used. The development results show that: 1) The process used in determining scholarship recipients is less able to produce optimal solutions by applying the weighted product method. 2) The results of the performance of the scholarship management system of students fall into the "Very Worthy" category. The percentage value of the test results on the system for each factor, namely: functionality of $88.8 \%$, efficiency of $86 \%$, and usability of $83 \%$. The total percentage of application quality is $86.2 \%$ (Very Worth).
\end{abstract}

Keywords: Scholarship, Mobile, Web, Prototype method, Weighted product method.

\begin{abstract}
ABSTRAK
Dalam menentukan penerima beasiswa peserta didik yang kurang mampu. Dimana setiap peserta didik yang ingin mengajukan beasiswa kurang mampu akan disurvey oleh Observer yang ditunjuk oleh pihak sekolah ke kediaman peserta didik, Dalam proses survey, Observer dibekali dengan instrumen penilaian yang harus diisi sesuai dengan kondisi nyata kediaman peserta didik. Hasil penilaian tersebut siberikan kepada pengelola beasiswa. Pokok masalah dalam pengembangan ini adalah proses yang digunakan dalam menentukan penerima beasiswa yang kurang optimal dan Cara yang dilakukan dalam mengolah data beasiswa peserta didik kurang efektif dan efisien. Tujuan dalam pengembangan ini adalah : Mengoptimalkan peoses penentuan penerima beasiswa dengan menerapkan metode weighted product dalam perhitungan nilai hasil survey serta Mengefektifkan dan mengefisiensikan cara pengolahan data beasiswa peserta didik kurang mampu da;am bentuk aplikasi. Metode yang digunakan dalam aplikasi ini adalah metode WP (Weighted product). Pelaksanaan Dalam pengembangan aplikasi digunakan metode Prototype. Hasil pengembangan menunjukan bahwa : 1) Proses yang digunakan dalam menentukan penerima beasiswa kurang mampu telah menghasilkan solusi optimal dengan menerapkan metode weighted product. 2) Hasil unjuk kerja sistem pengelolaan beasiswa peserta didik masuk dalam kategori "Sangat Layak". Nilai persentase hasil pengujian pada sistem untuk setiap faktor, yaitu : functionality sebesar 88,8\%, efficiency sebesar $86 \%$, dan usability sebesar $83 \%$. Persentase total dari kualitas aplikasi adalah 86,2 \% (Sangat Layak).
\end{abstract}

Kata Kunci: Beasiswa, Mobile, Web, metode Prototype, metode Weighted product 


\section{PENDAHULUAN}

\section{A. Latar Belakang}

Lembaga pendidikan seperti sekolah - sekolah sudah banyak memprogramkan beasiswa yang ditawarkan kepada peserta didik yang kurang mampu maupun peserta didik yang berprestasi. Seperti yang tertuang dalam Undang - Undang Dasar 1945 pasal 31 ayat 1 yang berbunyi "Bahwa Setiap warga negara berhak mendapat pendidikan". Sehingga pemerintah pusat dan pemerintah daerah wajib memberikan kemudahan kepada warga negara untuk mendapat pendidikan yang bermutu. Untuk mendapatkan pendidikan yang bermutu tentunya dibutuhkan biaya yang tidak sedikit. Oleh karena itu bagi peserta didik yang kurang mampu dalam pembiayaan sekolah maupun peserta didik berprestasi diberikan bantuan biaya pendidikan yang biasanya sering disebut beasiswa.

SMK Wikrama Bogor memiliki program beasiswa yang dilaksanakan setiap tahun untuk meringankan beban biaya pendidikan bagi peserta didik, ada beberapa jenis beasiswa yang tersedia, salahsatunya adalah beasiswa bagi peserta didik yang kurang mampu (dhuafa dan yatim). Beasiswa tersebut bersumber tidak hanya dari bantuan pemerintah, tetapi juga bersumber dari infaq dan shodaqoh dari yayasan, guru, staf dan orang tua peserta didik.

Dalam kebijakan suatu pemberian beasiswa kurang mampu tentunya tidak semua peserta didik mendapatkannya, karena terbatasnya sumber dana dan jumlah dana yang tersedia. Oleh karena itu SMK Wikrama Bogor telah menetapkan persyaratan dan kriteria khusus bagi peserta didik yang ingin mendapatkan beasiswa kurang mampu agar pemberian beasiswa jatuh ke peserta didik yang tepat. Salah satu upaya sekolah dalam memperoleh keakuratan tersebut adalah dengan melakukan survey ke kediaman peserta didik untuk mengetahui kondisi peserta didik yang sebenarnya, dimana survey tersebut dilakukan oleh guru yang ditunjuk oleh pihak sekolah. Hasil dari survey tersebut berupa data dikumpulkan dan diolah untuk menentukan apakah peserta didik tersebut layak atau tidak untuk mendapatkan beasiswa kurang mampu.

Banyak metode yang bisa digunakan dalam menyelesaikan masalah seleksi penerima beasiswa peserta didik yang kurang mampu, salahsatunya adalah Metode Weighted product. Metode ini merupakan metode yang digunakan dalam perangkingan nilai yang paling sederhana, dengan menggunakan perkalian untuk menghubungkan rating atribut, dimana rating harus dipangkatkan terlebih dahulu dengan bobot atribut yang bersangkutan. Selain itu atribut dalam weighted product berbentuk range tertentu dan sesuai dengan atribut survey yang digunakan dalam instrument survey beasiswa. Dengan menggunakan metode ini diharapkan proses seleksi calon penerima beasiswa peserta didik kurang mampu akan lebih efektif dan efisien.

\section{B. Rumusan Masalah}

Rumusan masalah yang dianalisa yaitu :

\section{Problem Statement}

Belum tersedianya sebuah solusi dalam pengelolaan beasiswa peserta didik yang dapat mengoptimalkan penentuan penerima beasiswa peserta didik kurang mampu.

\section{Research Question}

Bagaimana penerapan weighted product dalam mengoptimalkan penentuan penerima beasiswa peserta didik kurang mampu pada sistem informasi pengelolaan beasiswa peserta didik di SMK Wikrama Bogor? 


\section{Kerangka Pemikiran}

Penelitian ini dilakukan untuk mengoptimalkan penentuan penerima beasiswa peserta didik dengan menggunakan metode weighted product. Adapun kerangka pemikiran penelitian ini dapat dilihat pada Gambar 1.
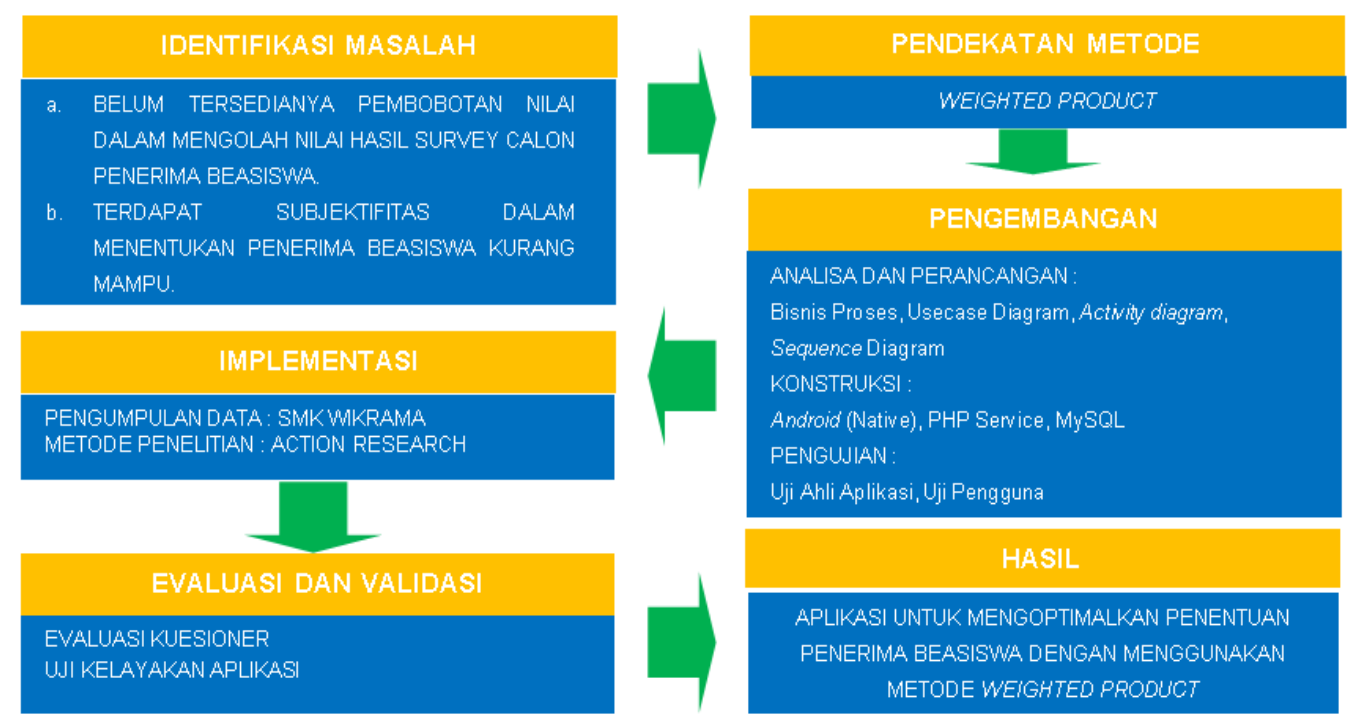

Gambar 1. Kerangka Pemikiran

1. Masalah yang diangkat dari penelitian ini yaitu belum tersedianya pembobotan nilai dalam mengolah nilai hasil survey calon penerima beasiswa. Terdapat juga subjektifitas dalam menentukan penerima beasiswa kurang mampu.

2. Pendekatan yang diusulkan yaitu dengan melakukan penerapan menggunakan metode weighted product

3. Tahap Pengembangan terdiri dari tiga kegiatan, yaitu :

a. Analisa dan perancangan dibuat dalam bentuk activity diagram, yaitu diagram yang menggambarkan beberapa alir aktivitas dalam sistem yang sedang dirancang, bagaimana masing-masing alir berawal, decision yang mungkin terjadi, dan bagaimana mereka berakhir. Activity diagram juga dapat menggambarkan proses paralel yang mungkin terjadi pada beberapa eksekusi. Proses bisnis, use case dan sequence diagram.

b. Konstruksi, aplikasi akan dibangun berbasis android native, php services sebagai serverside dan mysql digunakan sebagai database.

c. Pengujian yang dilakukan dalam penelitian ini adalah dengan uji ahli aplikasi dan uji pengguna aplikasi.

4. Tahap Implementasi terdiri dari dua kegiatan, yaitu :

a. Data yang akan dikumpulkan berasal dari data SMK Wikrama Bogor

b. Metode penelitian yang dipakai adalah action research, penelitian terdokumentasi dan dipantau dari upaya oleh peneliti untuk secara aktif memecahkan masalah dan mengubah situasi.

5. Tahap Evaluasi dan Validasi, yaitu :

a. Evaluasi kuesioner, menyebarkan beberapa kuesioner kepada 2 penguji ahli dan 3 pengguna aplikasi, kemudian saran/komentar dari penguji ahli akan dijadikan acuan dalam perbaikan aplikasi. 
b. Uji kelayakan aplikasi, aplikasi akan diuji dari segi aspek functionality, efficiency, dan usability.

6. Hasil yang didapat adalah aplikasi yang mampu menentukan penerima beasiswa peserta didik kurang mampu yang lebih optimal bagi pihak pengelola beasiswa.

\section{MODEL PENGEMBANGAN}

Dalam Penelitian yang dilakukan terdapat beberapa aspek yang menjadi pertimbangan dalam melakukan penelitian yaitu Metode penelitian yang pada dasarnya merupakan cara ilmiah untuk mendapatkan data dengan tujuan dan kegunaan tertentu (Sugiyono ,2012). Ogedebe, dkk (2012), menyampaikan bahwa prototyping merupakan metode pengembangan perangat lunak, yang berupa model fisik kerja sistem dan berfungsi sebagai versi awal dari sistem. Dengan metode prototyping ini akan dihasilkan prototype sistem sebagai perantara pengembang dan pengguna agar dapat berinteraksi dalam proses kegiatan pengembangan sistem informasi. Agar proses pembuatan prototype ini berhasil dengan baik adalah dengan mendefinisikan aturan-aturan pada tahap awal, yaitu pengembang dan penguna harus satu pemahaman bahwa prototype dibangun untuk mendefinisikan kebutuhan awal. Prototype akan dihilangkan atau ditambahkan pada bagiannya sehingga sesuai dengan perencanaan dan analisis yang dilakukan oleh pengembang sampai dengan ujicoba dilakukan secara simultan seiiring dengan proses pengembangan. Ada 4 metodologi prototyping yang paling utama yaitu :

1. Illustrative, menghasilkan contoh laporan dan tampilan layar.

2. Simulated, mensimulasikan beberapa alur kerja sistem tetapi tidak menggunakan data real.

3. Functional, mensimulasikan beberapa alaur sistem yang sebenarnya dan menggunakan data real.

4. Evolutionary, menghasilkan model yang menjadi bagian dari operasional sistem.

Dibuatnya sebuah Prototyping bagi pengembang sistem bertujuan untuk mengumpulkan informasi dari pengguna sehingga pengguna dapat berinteraksi dengan model prototype yang dikembangkan, sebab prototype menggambarkan versi awal dari sistem untuk kelanjutan sistem sesungguhnya yang lebih besar. Ogedebe (2012), menegaskan: Telah ditemukan bahwa dalam analisis dan desain sistem, terutama untuk proses transaksi, di mana dialog yang ditampilkan lebih mudah difahami. Semakin besar interaksi antara komputer dan pengguna, besar pula manfaat yang diperoleh ketika proses pengembangan sistem informasi akan lebih cepat dan membuat pengguna akan lebih interaktif dalam proses pengembangannya.

\section{HASIL DAN PEMBAHASAN}

\section{A. Analisa Kebutuhan}

Langkah pertama yang dilakukan pada penelitian ini adalah pengumpulan kebutuhan, dimana diadakan diskusi antara pihak pengembang dan pelanggan. Sistem ini dibuat untuk memudahkan proses pengelolaan data maupun informasi dalam pengelolaan beasiswa dan sebagai alat untuk mendukung proses pengambilan keputusan bagi pihak sekolah dalam menentukan penerima beasiswa peserta didik kurang mampu. Pada sistem ini terdapat 2 jenis pengguna yang akan menggunakan sistem pengelolaan beasiswa, yaitu Administrator dan Observer. Untuk Administrator terdapat beberapa fitur yang dapat diakses yaitu dalam pengelolaan data pengajuan, data Observer, kuota beasiswa, instrument survey, penunjukan Observer untuk melakukan survey, melihat hasil survey, dan menentukan penerima beasiswa yang didukung oleh rekomendasi dari sistem, serta melihat laporan penerima beasiswa. Untuk Observer terdapat beberapa fitur yang dapat diakses seperti melihat data Observer, melakukan proses survey dan melihat hasil survey sesuai dengan pengelompokan. Melihat banyaknya fitur dalam sistem yang akan dibuat dibutuhkan beberapa data untuk membangun sistem pengelolaan beasiswa peserta didik agar sesuai dengan harapan diantaranya : Data Pengajuan Beasiswa, Data Observer, Data Kuota Beasiswa, Data Instrumen Survey, Data Hasil Survey dan Laporan Penerima Beasiswa. 


\section{Penerapan Metode Weigthed Product}

Dalam proses pengolahan nilai menggunakan weighted product, dapat dijelaskan pada tampilan flowchart berikut ini:

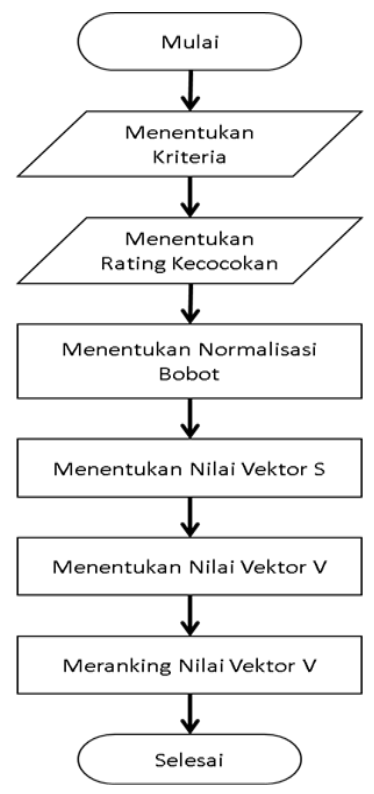

Gambar 1. Flowchart Weighted Product

Pada langkah ini tidak hanya dibutuhkan data berupa form-form manual yang sudah ada, tetapi terdapat pula beberapa analisa kebutuhan yang diperlukan agar sistem yang dibuat sesuai dengan harapan. Dengan berpedoman pada UML (Unified Modelling Language) maka terdapat beberapa kebutuhan yang harus dibuat oleh pengembang.

\section{Usecase Diagram}

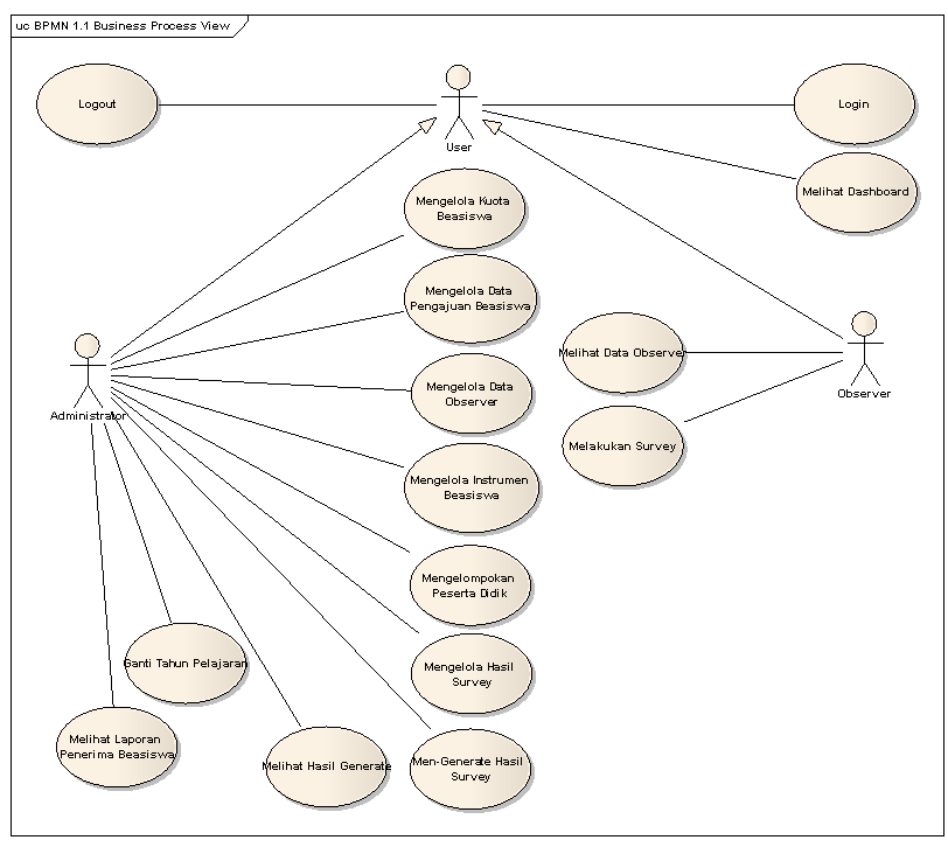

Gambar 3. Usecase Diagram 


\section{Activity Diagram}

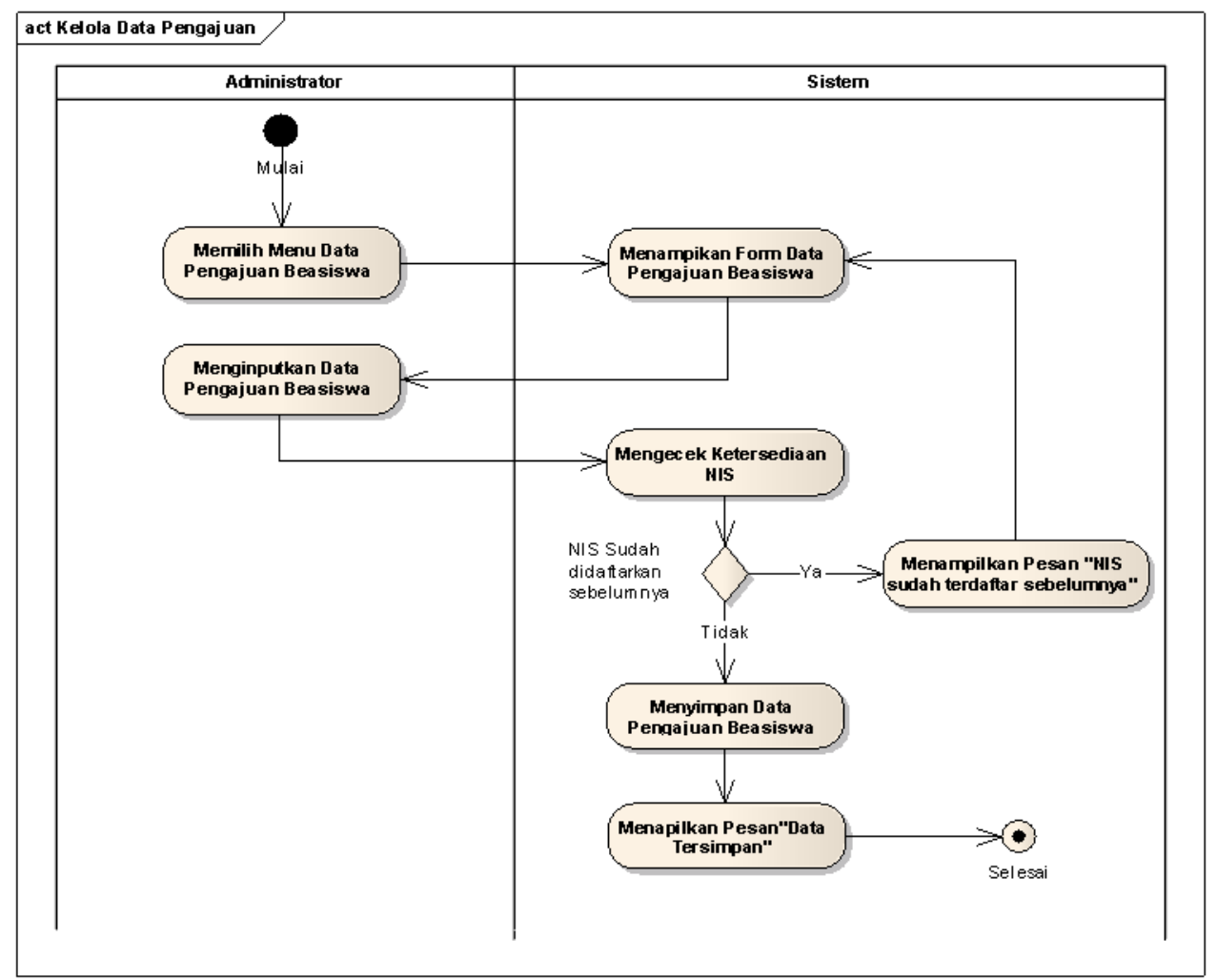

Gambar 4. Activity Diagram

\section{B. Hasil}

Hasil dari penelitian ini adalah produk aplikasi yang menerapkan metode WP (Weighted product) yang berfungsi untuk :

1. Mengoptimalkan penentuan penerima beasiswa dalam perhitungan nilai hasil survey.

2. Mengefektifkan dan mengefisiensikan cara pengolahan data beasiswa peserta didik kurang mampu melalui sistem pengelolaan beasiswa.

Pada Aplikasi ini telah dilakukan Uji Kelayakan Perangkat Lunak dari Aspek Functionality, Efficiency, dan Usability, dengan hasil seperti pada Tabel 1.

Tabel 1. Hasil Uji Kelayakan Aspek Functionality, Efficiency, dan Usability

\begin{tabular}{|c|c|c|c|c|c|c|}
\hline \multirow{2}{*}{ No } & \multirow{2}{*}{ Pernyataan } & \multicolumn{2}{|c|}{ Ahli } & \multicolumn{3}{|c|}{ Pengguna } \\
\hline & & $\begin{array}{l}\text { Nilai } \\
\text { Penguji } 1\end{array}$ & $\begin{array}{l}\text { Nilai } \\
\text { Penguji } 2\end{array}$ & $\begin{array}{l}\text { Nilai } \\
\text { Penguji } 3\end{array}$ & $\begin{array}{l}\text { Nilai } \\
\text { penguji } 4\end{array}$ & $\begin{array}{l}\text { Nilai } \\
\text { penguji } 5\end{array}$ \\
\hline \multicolumn{7}{|c|}{ Aspek Functionality } \\
\hline 1. & $\begin{array}{l}\text { Perangkat lunak dapat } \\
\text { memasukan data }\end{array}$ & 5 & 4 & 5 & 5 & 5 \\
\hline 2. & Perangkat lunak dapat & 5 & 4 & 5 & 4 & 5 \\
\hline
\end{tabular}




\begin{tabular}{|c|c|c|c|c|c|c|}
\hline & $\begin{array}{l}\text { menampilkan semua } \\
\text { data }\end{array}$ & & & & & \\
\hline 3. & $\begin{array}{l}\text { Setiap tombol berfungsi } \\
\text { sesuai dengan fungsinya } \\
\text { masing-masing }\end{array}$ & 5 & 4 & 5 & 5 & 4 \\
\hline 4. & $\begin{array}{l}\text { Perangkat lunak dapat } \\
\text { menyimpan data ke } \\
\text { dalam database dengan } \\
\text { baik }\end{array}$ & 5 & 5 & 5 & 4 & 4 \\
\hline 5. & $\begin{array}{l}\text { Perangkat lunak dapat } \\
\text { menampilkan map } \\
\text { dengan titik-titik lokasi } \\
\text { pelanggan dan teknisi } \\
\text { dengan tepat }\end{array}$ & 5 & 5 & 5 & 5 & 5 \\
\hline \multicolumn{7}{|c|}{ Aspek Efficiency } \\
\hline 6. & $\begin{array}{l}\text { Tiap proses } \\
\text { membutuhkan jeda waktu } \\
\text { yang singkat }\end{array}$ & 5 & 4 & 5 & 4 & 5 \\
\hline 7. & $\begin{array}{l}\text { Respon dari setiap } \\
\text { proses sesuai dengan } \\
\text { fungsinya masing-masing }\end{array}$ & 5 & 4 & 5 & 5 & 4 \\
\hline \multicolumn{7}{|c|}{ Aspek Usability } \\
\hline 8. & $\begin{array}{l}\text { Kemudahan dalam } \\
\text { mempelajari penggunaan } \\
\text { sistemnya }\end{array}$ & 5 & 4 & 5 & 5 & 5 \\
\hline 9. & $\begin{array}{ll}\text { Kejelasan } & \text { dalam } \\
\text { mengoperasikan } & \\
\text { sistemnya } & \end{array}$ & 5 & 4 & 5 & 5 & 4 \\
\hline 10. & $\begin{array}{l}\text { Memberikan informasi } \\
\text { yang mudah dipahami }\end{array}$ & 5 & 5 & 5 & 5 & 5 \\
\hline 11. & $\begin{array}{l}\text { Data dan informasi yang } \\
\text { sudah sesuai }\end{array}$ & 5 & 4 & 5 & 4 & 5 \\
\hline & Jumlah & 55 & 47 & 55 & 51 & 51 \\
\hline & Nilai Tertinggi & 55 & 55 & 55 & 55 & 55 \\
\hline
\end{tabular}


Tabel 2. Hasil Perhitungan Uji Kelayakan

\begin{tabular}{|c|c|c|c|}
\hline Responden & Functionality & Efficiency & Usability \\
\hline 1 & 25 & 10 & 20 \\
\hline 2 & 22 & 8 & 17 \\
\hline 3 & 25 & 10 & 20 \\
\hline 4 & 23 & 9 & 19 \\
\hline 5 & 23 & 9 & 19 \\
\hline Total Skor & 118 & 46 & 95 \\
\hline Skor Maksimum & 125 & 50 & 100 \\
\hline Persentase & 94,4 & 92 & 95 \\
\hline
\end{tabular}

Rumus perhitungan untuk mendapatkan nilai total skor, skor maksimum, dan persentase adalah sebagai berikut :

Total Skor Functionality $=f 1+f 2+f 3+f 4+f 5$

Total Skor Efficiency $=f 1+f 2+f 3+f 4+f 5$

Total Skor Usability $=f 1+f 2+f 3+f 4+f 5$

\section{Skor Maksimum :}

$=$ nilai tertinggi *jumlah nilai per kriteria *jumlah penguji

Persentase Per Faktor $=\frac{\text { tota }[\mathrm{skor}}{s \mathrm{kor} \text { tha } \mathrm{ksitmu+n}} * 100$

Perhitungan persentase faktor kualitas perangkat lunak kemudian digambarkan dalam bentuk diagram. Dapat dilihat pada Gambar 5.

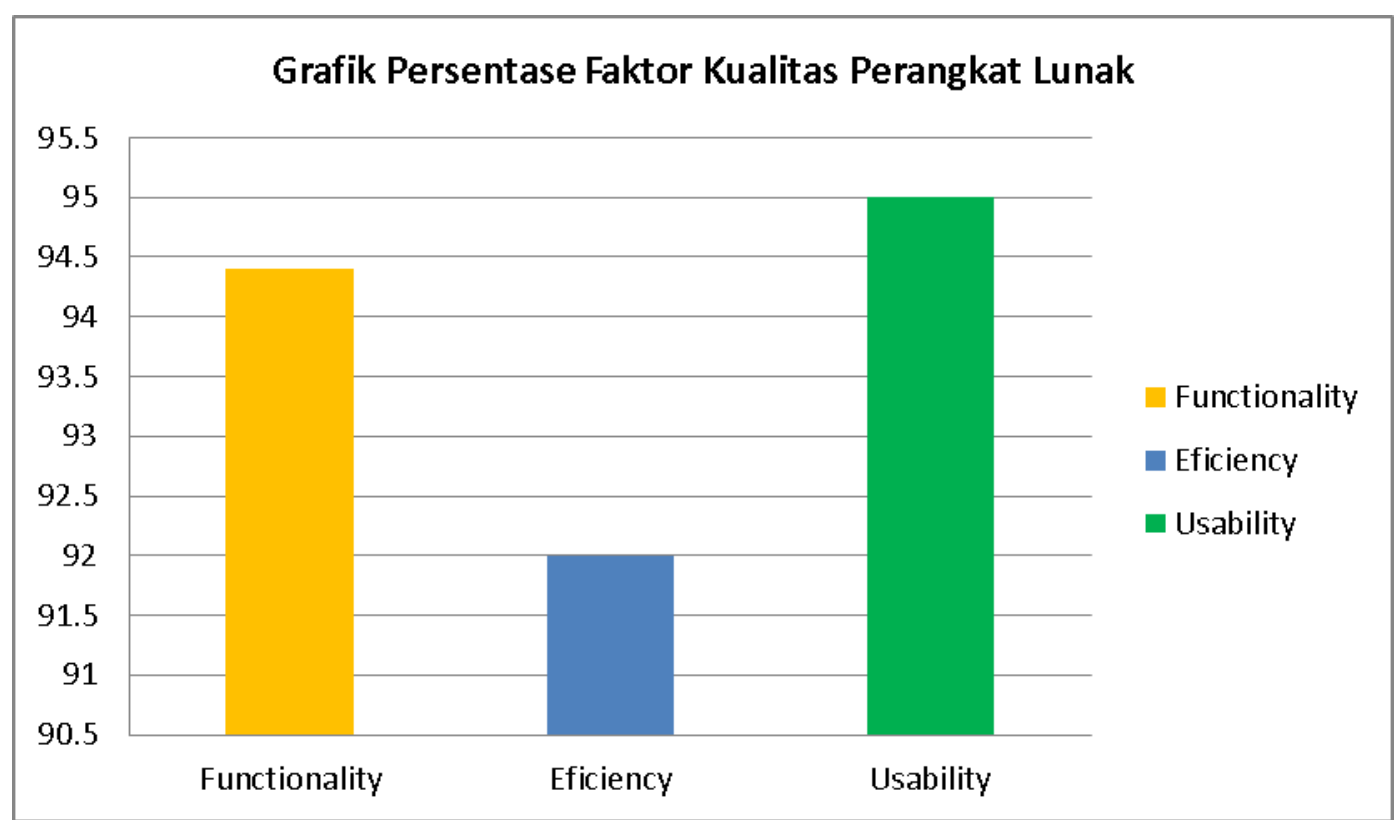

Gambar 5. Persentase Kualitas Aplikasi 
Hasil perhitungan untuk mengetahui kualitas perangkat lunak dari segi functionality, efficiency, dan usability.

Tingkat kelayakan masing-masing faktor kualitas perangkat lunak setelah membandingkan dengan tabel interpretasi persentase kelayakan perangkat lunak dapat dilihat pada Tabel dibawah ini.

Perhitungan persentase kualitas sistem secara keseluruhan dari data yang didapatkan sebagai berikut :

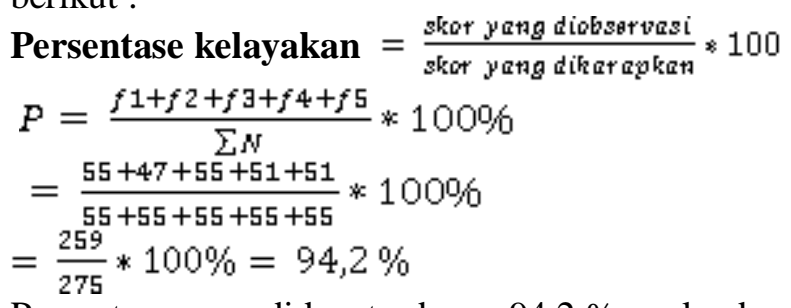

Persentase yang didapat sebesar 94,2 \%, maka dapat dikategorikan Sangat Layak.

\section{SIMPULAN}

Hasil penelitian ini adalah sistem pengelolaan beasiswa peserta didik dengan menggunakan metode weighted product untuk sebagai rekomendasi kepada pihak sekolah dalam menentukan peserta didik yang berhak menerima beasiswa kurang mampu. Berdasarkan hasil dari implementasi sistem maka dapat disimpulkan bahwa:

1. Proses dan fungsi yang digunakan dalam menentukan penerima beasiswa kurang mampu telah menghasilkan solusi optimal dengan menerapkan metode weighted product.

2. Hasil unjuk kerja sistem pengelolaan beasiswa peserta didik masuk dalam kategori "Sangat Layak". Nilai persentase hasil pengujian pada sistem untuk setiap faktor, yaitu : functionality sebesar $88,8 \%$, efficiency sebesar $86 \%$, dan usability sebesar $83 \%$. Persentase total dari kualitas aplikasi adalah 86,2 \% (Sangat Layak).

\section{DAFTAR RUJUKAN}

Arikunto, S. (2002). Prosedur Penelitian Suatu Pendekatan Praktek. Jakarta: Rineka Cipta.

Artanti Rim Saulina Manik, Bowo Nurhadiyono, Yuniarsi Rahayu. 2015. Jurnal Implementasi Metode Weighted product Dalam Sistem Pendukung Keputusan Untuk Menyeleksi Penerima Beras Masyarakat Miskin (raskin). Universitas Dian Nuswantoro.

Aziz Ahmadi. Jurnal Implementasi Weighted product (WP) Dalam Penentuan Penerima Bantuan Langsung Masyarakat PNPM Mandiri Perdesaan. STKIP PGRI.

Cepi Rahmat Hidayat, Teuku Mufizar, Muhamad Dadan Ramdani . 2018 (Implementasi Metode Weighted Product (Wp) Pada Sistem Pendukung Keputusan Seleksi Calon Karyawan Bpjs Kesehatan Tasikmalaya, Teknik Informatika, STMIK Tasikmalaya)

Dwi Cahyanto Yoni, Hindayati Mustafidah. 2016. Jurnal Penerapan Metode WP (Weighted product) Untuk Pemilihan Mahasiswa Lulusan Terbaik di Fakultas Teknik Universitas Muhammadiyah Purwokerto. Universitas Muhammadiyah Purwokerto.

Dyna Marisa Khairina, Dio Ivando, Septya Maharani. 2016. Jurnal Implementasi Metode Weighted product Untuk Aplikasi Pemilihan Smartphone Android. Universitas Mulawarman.

Fahmy, Syahrul, Haslinda Nurul, et.al. "Evaluating the Quality of Software in e-Book Using the ISO 9126 Model." International Journal of Control and Automation 5 (2012).

Fernandi, E., Alfandri, F., Putri, G. A., \& Mathias, R. (2013). Analisis dan Desain Berorientasi Objek (OOAD) dan Diagram Activity. Depok: Universitas Gunadarma. 
Fx. Eko Budi Kristanto. 2013. Kualitas Perangkat Lunak Model ISO 9126. http://fxekobudi.net/ilmukomputer/kualitas-perangkat-lunak-model-iso-9126/

Kusumadewi, S., Hartati, S., Harjoko A., Wardoyo R., 2006, Fuzzy Multi-Attribute Decision Making (Fuzzy MADM), Graha Ilmu, Yogyakarta

Modulmakalah. (2015). "Pengertian dan Contoh Analisis Isi Dalam Metode Penelitian". Dipetik Juli 11, 2017, dari http://modulmakalah.blogspot.co.id/2015/11/pengertian-dan- contoh-analisis- isi.html 